\title{
Antimicrobial Cluster Bombs: Silver Nanoclusters Packed with Daptomycin
}

Kaiyuan Zheng, ${ }^{a}$ Magdiel I. Setyawati, ${ }^{a} *$ Tze-Peng Lim, ${ }^{b, c}$ David Tai Leong ${ }^{a} *$ and Jianping Xie $a$ *

${ }^{a}$ Department of Chemical and Biomolecular Engineering, National University of Singapore, 4 Engineering Drive 4, Singapore 117585, Singapore

${ }^{\mathrm{b}}$ Department of Pharmacy, Singapore General Hospital, Outram Road, 169608, Singapore

${ }^{\mathrm{c}}$ Office of Clinical Sciences, Duke-NUS Medical School, 8 College Road, 169857, Singapore 


\section{Supporting Information}

\section{EXPERIMENTAL SECTION}

\section{Bacterial Cell Culture}

S. aureus was cultured in LB medium in shaker of $37^{\circ} \mathrm{C}, 180 \mathrm{rpm}$. Maintenance of $S$. aureus was conducted by growing the cells on LB agar (15\% w/v agar in LB medium). For each experiment, a single colony of $S$. aureus was picked from the fresh $\mathrm{LB}$ agar plate and cultured at $37{ }^{\circ} \mathrm{C}, 180$ $\mathrm{rpm}$ for $\sim 16 \mathrm{~h}$ in LB medium. The cultured bacteria were then used for the following experiments.

\section{Bacterial Cells Growth}

The cultured $S$. aureus was introduced to the fresh LB medium at the concentration of $\mathrm{OD}_{600}$ of 0.1 (approximately $2 \times 10^{6}-5 \times 10^{6} \mathrm{CFU} \cdot \mathrm{mL}^{-1}$ ). After that, $800 \mu \mathrm{L}$ of the bacterial solution was added in a round bottom tube, and $200 \mu \mathrm{L}$ of $\mathrm{AgNCs}$ solution ( $1 \mathrm{mM}$ on the basis of $\mathrm{Ag}$ atoms) or other control solutions (water or $10 \mu \mathrm{M}$ Daptomycin) was also added in the tube. The cells were then incubated at $37{ }^{\circ} \mathrm{C}, 180 \mathrm{rpm}$. The concentration of bacterial cells at beginning and after treatment of $1 \mathrm{~h}$ and $2 \mathrm{~h}$ were recorded through measuring the $\mathrm{OD}_{600}$ with triplicate. For each treatment group, the $\mathrm{OD}_{600}$ value following $1 \mathrm{~h}$ or $2 \mathrm{~h}$ treatment was corrected to their respective initial $\mathrm{OD}_{600}$ value (the AgNC solutions could also contribute to the absorption at $600 \mathrm{~nm}$ ). The corrected value was then normalized to the $\mathrm{OD}_{600}$ value of the water-treated group at $\mathrm{t}=0 \mathrm{~h}$ to yield the relative bacterial growth after treatment.

$$
\mathrm{OD}_{\text {relative }}=\left(\mathrm{OD}_{\text {sample, } \mathrm{t}}-\mathrm{OD}_{\text {sample, } 0 \mathrm{~h}}\right) / \mathrm{OD}_{\text {water, } 0 \mathrm{~h}}
$$

\section{Intracellular Reactive Oxygen Species (ROS) Generation}

DCFH-DA dye was applied to test the intracellular ROS concentration, which could be cleaved by the intracellular nonspecific esterase into DCFH form. The DCFH in the presence of ROS would be further oxidized into fluorescent DCF. The bacterial cells were incubated with AgNC 
solutions for $\sim 2 \mathrm{~h}$, then $5 \mu \mathrm{M}$ DCFH-DA and $1 \mu \mathrm{g} \mathrm{mL} \mathrm{m}^{-1}$ Hoechst 33342 were added to the bacterial mixture, and further incubated at $37{ }^{\circ} \mathrm{C}, 180 \mathrm{rpm}$ for $\sim 15 \mathrm{~min}$. After that, the bacterial cells suspension was centrifuged at $10000 \times \mathrm{g}$ for $2 \mathrm{~min}$, washed three times with ultrapure water, and re-suspended in ultrapure water to the original volume $(1 \mathrm{~mL})$. The concentration of the asproduced DCF was measured by the microplate reader at excitation/emission wavelength of $488 / 525 \mathrm{~nm}$, since the fluorescence intensity of DCF directly reflects the amount of ROS generation. The ROS amount was then normalized to the total cell number, which was reflected by the fluorescence intensity of Hoechst 33342 (excitation/emission wavelength = 350/461 nm). The relative ROS production level was calculated by normalizing the ROS level from the treated groups with the production level on the water-treated group. Similarly, for the NAC-treated group, $25 \mathrm{mM}$ NAC was added together with $\mathrm{AgNCs}$, and the mixture was incubated for $2 \mathrm{~h}$, keeping all the other steps the same.

\section{Measurement of ROS in the Cell Free System}

AgNCs were incubated in LB without the bacterial cells for $2 \mathrm{~h}$ (the same concentration as in other experiments), where $200 \mathrm{nM} \mathrm{H} \mathrm{O}_{2}$ was used as a positive control. The measurement of ROS was conducted through the manufacturer's protocol. In particular, $50 \mu \mathrm{L}$ of sample was first added in the microplate, and $50 \mu \mathrm{L}$ of the Amplex ${ }^{\circledR}$ Red reagent/HRP working solution $(100 \mu \mathrm{M}$ Amplex ${ }^{\circledR}$ Red reagent and $0.2 \mathrm{U} / \mathrm{mL}$ HRP) was mixed with the sample. The mixture was incubated at room temperature for $30 \mathrm{~min}$ without light. The amount of the as-produced ROS was then measured by the microplate reader at an excitation/emission wavelength of 571/585 $\mathrm{nm}$.

\section{Bacterial Membrane Damage}

Propidium iodide (PI) was used to assess the membrane damage on the bacterial cell. PI is cell impermeable which leads to a high uptake on dead cells with compromised membrane, leaving the healthy cell to be unstained by the PI. The bacterial cells were incubated with AgNC solutions for $\sim 2 \mathrm{~h}$, then $30 \mu \mathrm{g} \mathrm{mL}^{-1}$ PI was added in each bacterial solution and incubated in shaker at $37^{\circ} \mathrm{C}, 180 \mathrm{rpm}$ for $15 \mathrm{~min}$. Later, the bacterial cells were centrifuged at $10000 \times \mathrm{g}$ for 2 min, washed three times with ultrapure water, and re-suspended in ultrapure water to the original volume. Finally, the bacterial cells were fixed on slides by 4\% paraformaldehyde in PBS for 15 
min, then $1 \mu \mathrm{g} \mathrm{mL}^{-1}$ Hoechst 33342 solution was added on slides for $15 \mathrm{~min}$, and ProLong® Gold antifade reagent with DAPI was also added. The bacterial cells were observed under epifluorescent microscope, and the cell numbers of PI stained bacteria and Hoechst 33342 stained bacteria were counted. The percentage of PI stained bacteria was then calculated from the PI stained bacteria number divided by the Hoechst 33342 stained bacteria number. In addition, the PI intensity of 100 bacterial cells from the D+AgNCs group and D-AgNCs group were counted by using ImageJ. The amount of PI inside the individual bacterial cells indicates the degree of bacterial membrane damage. Similarly, for the NAC-treated group, $25 \mathrm{mM}$ NAC was added together with AgNCs, and the mixture was incubated for $2 \mathrm{~h}$, keeping all the other steps the same.

\section{Measurement of AgNCs Uptake}

The bacteria were treated with AgNCs for $2 \mathrm{~h}$ and then they were washed thrice to remove any residual AgNCs that were not internalized inside the bacteria. Following that the bacteria were collected and freeze dried. The freeze dried cell pellet was then digested by aqua regia and the solution was used to analyze the Ag content by ICP-OES. The as-measured Ag content was then normalized back to the dry weight of the cell pellet (DWC).

\section{Bacterial DNA Damage}

\subsection{Genomic DNA Extraction and PAGE}

The genomic DNA of bacteria was extracted by GenElute ${ }^{\mathrm{TM}}$ Bacterial Genomic DNA Kits according to the manufacturer's instructions. Generally, the bacterial cells, which were incubated with the AgNC solutions for $\sim 2 \mathrm{~h}$, were centrifuged down, and then re-suspended in $2.115 \times 10^{6}$ unit/mL lysozyme solution with 200 unit/mL lysostaphin, followed by incubation for $30 \mathrm{~min}$ at $37{ }^{\circ} \mathrm{C}$. Next, proteinase K solution and the lysis solution were added in the solutions, followed by incubation for $10 \mathrm{~min}$ at $55{ }^{\circ} \mathrm{C}$. After that, a binding column was used to bind the DNA and the column was washed. Finally, an elution solution was used to elute the extracted genomic DNA. After the genomic DNA was extracted, $200 \mathrm{ng}$ DNA of each sample was separated on a $6 \mathrm{wt} \%$ native polyacrylamide gel electrophoresis (PAGE). The electrophoresis was allowed to run for $\sim 3 \mathrm{~h}$ at a fixed voltage of $150 \mathrm{~V}$ at $4{ }^{\circ} \mathrm{C}$. 


\subsection{RecA Gene Expression}

RNA of the bacteria was extracted by NucleoSpin RNA Kit (Macherey-Nagel, USA) according to the protocol of the manufacturer. The extracted RNA was converted to cDNA by using iScript $^{\mathrm{TM}}$ cDNA Synthesis Kit (Bio-Rad, USA) according to the manufacturer's instructions. The quantitative PCR was conducted in CFX96 ${ }^{\mathrm{TM}}$ Real-Time PCR Detection System (Bio-Rad, USA) with SsoAdvanced SYBR Green Supermix kit (Bio-Rad, USA). The recA gene expression was normalized to the expression of the housekeeping gene, gyrB. The primer sequences of each gene were listed in Table S1. Similarly, for the NAC-treated group, $25 \mathrm{mM} \mathrm{NAC}$ was added together with AgNCs, and the mixture was incubated for $2 \mathrm{~h}$, keeping all the other steps the same.

Table S1. RT-PCR primers.

\begin{tabular}{|l|l|l|}
\hline Gene & Forward primer 5' to 3' & Reverse primer 5' to 3' \\
\hline recA & GAAGTACAAAGTAATGGCGGGGT & AATGCTTCAGCGATTTCAAGA \\
\hline gyrB & TCAATACAGGTTTTAGAGGGGTTA & AACCATTCAATACTTCATCGACG \\
\hline
\end{tabular}

\subsection{Terminal Deoxynucleotidyl Transferase dUTP Nick End Labeling (TUNEL) Test}

TUNEL test was conducted through the manufacturer's protocol. Firstly, the bacterial cells incubated with AgNC solutions for $\sim 2 \mathrm{~h}$ were fixed on slides with $4 \%$ paraformaldehyde in PBS for $15 \mathrm{~min}$, and permeabilized with 2\% Triton X-100 in PBS for $20 \mathrm{~min}$. The positive control was prepared by using a $5 \mathrm{unit} / \mathrm{mL}$ DNaseI solution to incubate for $30 \mathrm{~min}$ at room temperature. Next, TdT reaction was conducted by adding TdT reaction buffer and incubating for $10 \mathrm{~min}$ at room temperature, followed by adding TdT reaction cocktail to incubate for $60 \mathrm{~min}$ at $37{ }^{\circ} \mathrm{C}$. Then, the slides were washed, and Click-iT® reaction was conducted through adding Click-iT® reaction cocktail to incubate for $30 \mathrm{~min}$ at room temperature protected from light. Finally, $1 \mu \mathrm{g}$ $\mathrm{mL}^{-1}$ Hoechst 33342 solution was added on slides for $15 \mathrm{~min}$, and ProLong ${ }^{\circledR}$ Gold antifade reagent with DAPI was also added. The bacterial cells were observed under epifluorescence microscope. For better contrast, the signal obtained from the Hoescht 33342 was reassigned to red. Then, the areas of green and red color were measured individually through ImageJ, and the ratio between the green and red area was taken to represent the ratio of DNA damaged bacteria towards normal bacteria. 


\section{Lipid Peroxidation Test}

Lipid peroxidation test was conducted through the manufacturer's protocol. Firstly, the bacterial cells incubated with AgNC solutions for $\sim 2 \mathrm{~h}$ were centrifuged at $10000 \times \mathrm{g}$ for $2 \mathrm{~min}$, washed three times with ultrapure water, and centrifuged down. Then, the bacterial cells were homogenized in $300 \mu \mathrm{L}$ of Lysis Buffer (2\% SDS) using ultrasonicator, and centrifuged at $13,000 \times \mathrm{g}$ for $10 \mathrm{~min}$ to remove the insoluble contents. Secondly, $200 \mu \mathrm{L}$ of supernatant was mixed with $600 \mu \mathrm{L}$ of Thiobarbituric Acid (TBA) reagent, and the mixture was incubated at 95 ${ }^{\circ} \mathrm{C}$ for $60 \mathrm{~min}$, followed by cooling in ice bath for $10 \mathrm{~min}$. Finally, $300 \mu \mathrm{L}$ of n-butanol with 100 $\mu \mathrm{L}$ of $5 \mathrm{M} \mathrm{NaCl}$ was added to the mixture, and the mixture was centrifuged at $16,000 \times \mathrm{g}$ for 3 min. The top layer containing n-butabol was then transferred to a new tube, followed by the evaporation of n-butanol. The pellet (the MDA-TBA adducts) was then dissolved in $200 \mu \mathrm{L}$ of ultrapure water. The amount of the as-produced MDA was measured by the microplate reader at an excitation/emission wavelength of 532/553 nm. The MDA concentration was then normalized to the total cell number through their $\mathrm{OD}_{600}$ value. The relative MDA concentration, which is also the lipid peroxidation level, was calculated by normalizing the MDA concentration from the treated groups with the water-treated group.

\section{Statistical Analysis}

All analysis were conducted in triplicate, and mean \pm standard deviation (SD) was reported. Statistical significance was ascertained with paired sample using Student's t-test comparison. Results were considered as statistically significant with $\mathrm{p}<0.05$.

\section{Size of Daptomycin}

We adopted the ChemDraw file of daptomycin from ref. $1,{ }^{1}$ and estimated the approximate size of daptomycin by measuring the atom distance between two atoms at opposite sites using ChemDraw. Several atom configurations were measured and the approximate size of daptomycin was determined to be $2-3 \mathrm{~nm}$. An example was shown in Figure S2, in which the atom distance between the marked $\mathrm{N}$ and $\mathrm{O}$ was measured to be $2.6 \mathrm{~nm}$. This size is comparable to the size of AgNCs which are about $2 \mathrm{~nm}$. 


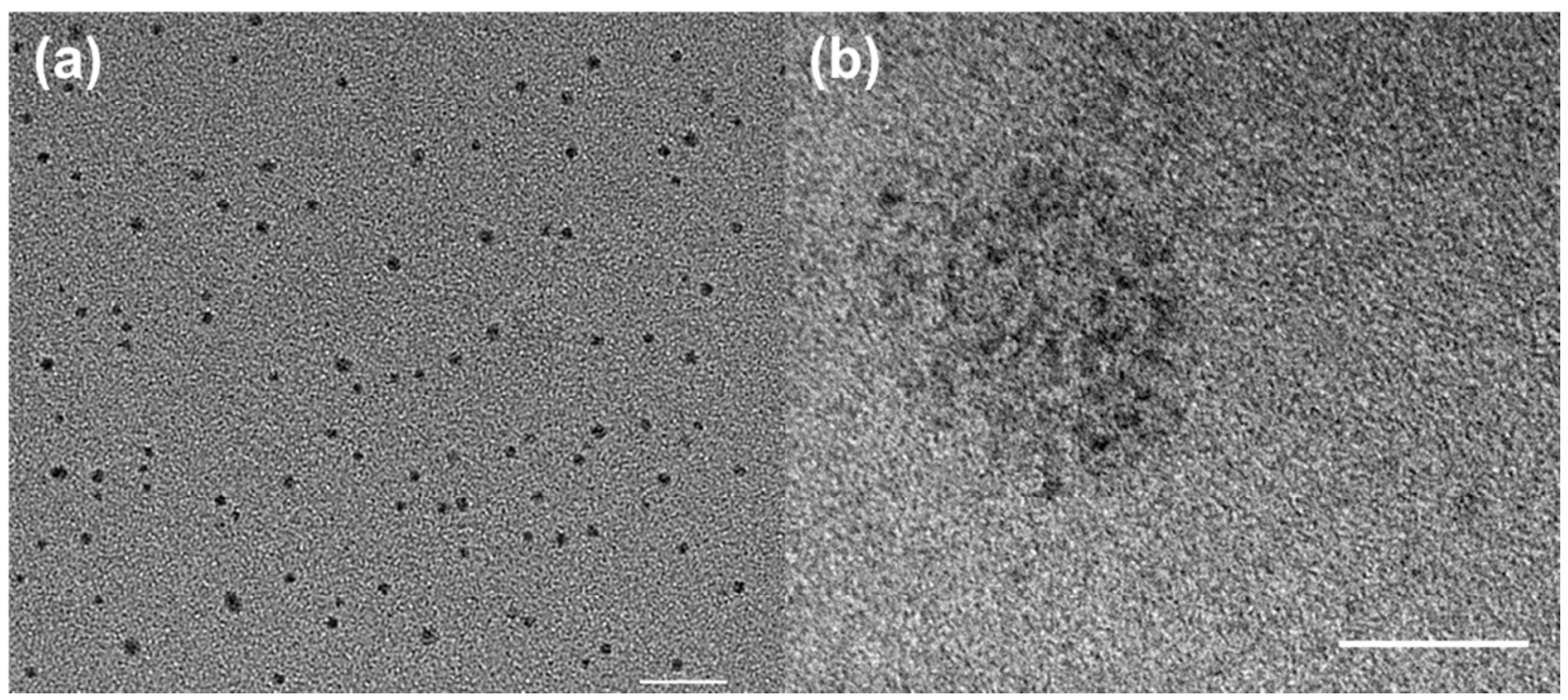

Figure S1. Representative TEM images of the as-prepared (a) AgNCs (scale bar: $20 \mathrm{~nm}$ ) and (b) D-AgNCs (scale bar: $50 \mathrm{~nm}$ ). TEM images indicate no obvious changes in the size of AgNCs after the conjugation process.

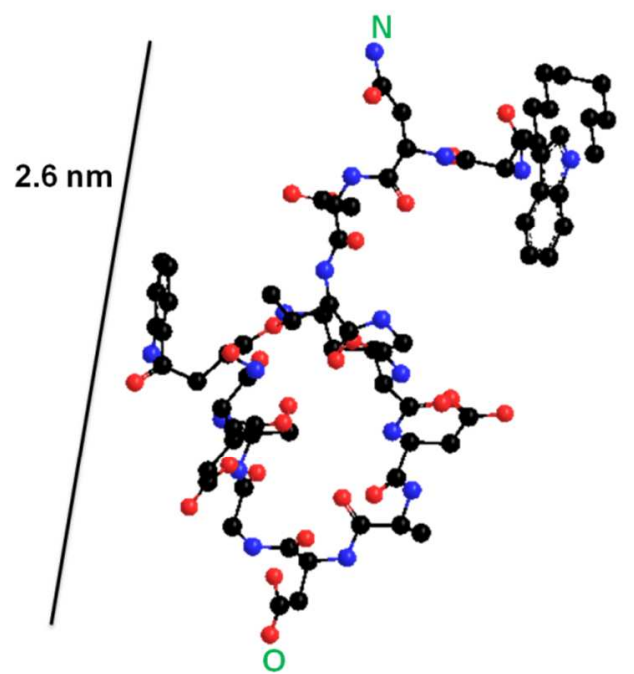

Figure S2. Molecular structure of daptomycin. Colour scheme: black, carbon; red, oxygen; blue, nitrogen. 


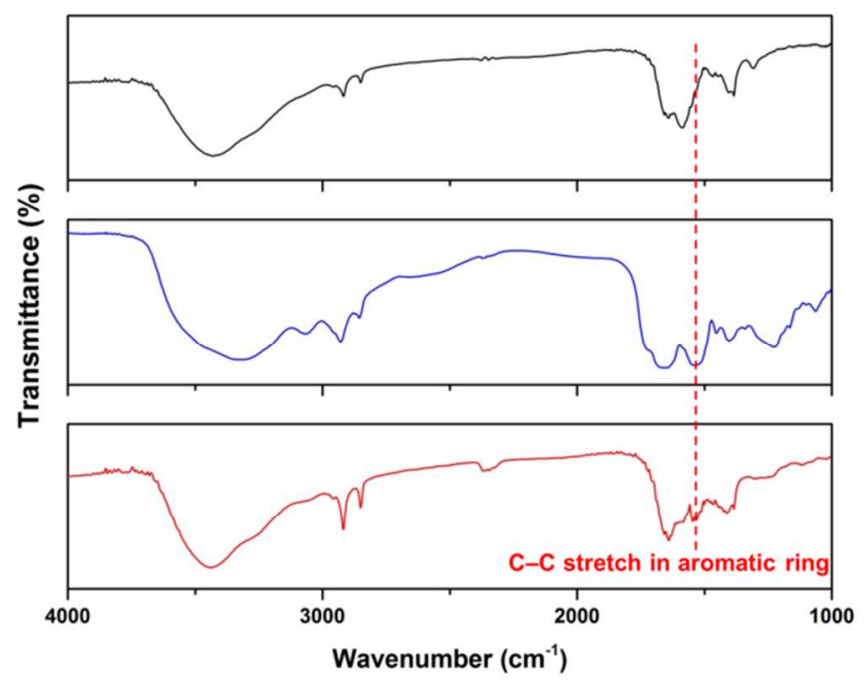

Figure S3. FTIR spectra of AgNCs protected by GSH (black line), daptomycin (blue line), and D-AgNCs (red line).
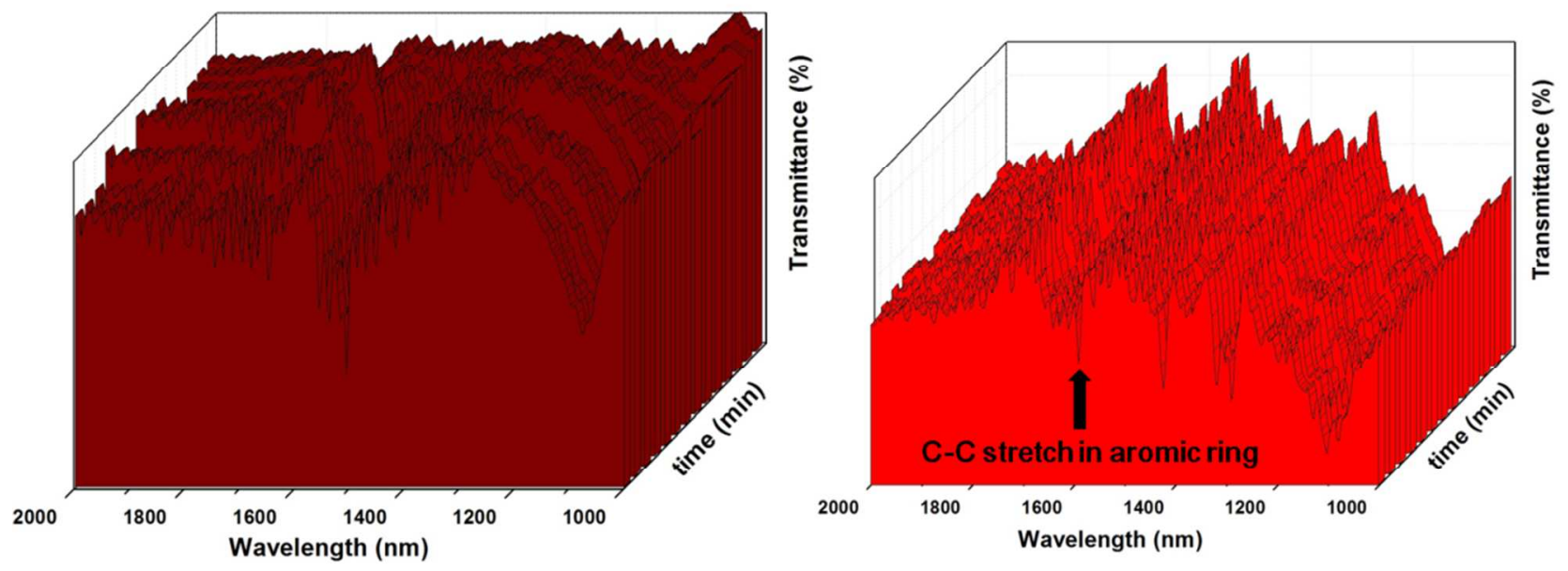

Figure S4. TGA-FTIR analysis (in $\mathrm{N}_{2}$ ) of the as-prepared (a) AgNCs and (b) D-AgNCs. The FTIR spectra showed that the ligands have dropped out during heating process. D-AgNCs showed the peak of C-C stretch in the aromatic ring at $\sim 1520 \mathrm{~cm}^{-1}$, while AgNCs did not possess, suggesting the existence of daptomycin inside the D-AgNCs. 


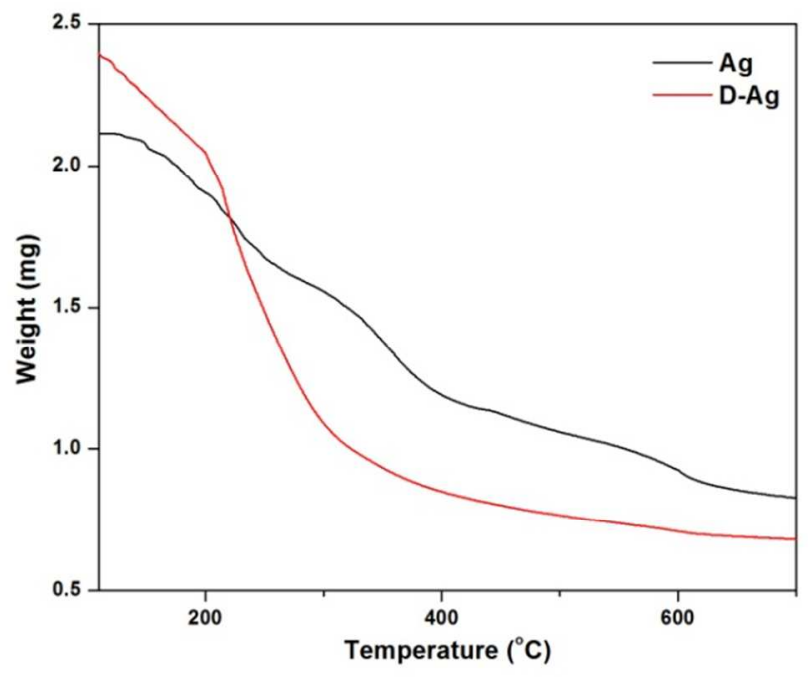

Figure S5. TGA analysis (in $\mathrm{N}_{2}$ ) of AgNCs (black line) and D-AgNCs (red line). The weight percentage of GSH ligands in AgNCs protected by GSH was estimated to be 62\%, which agrees well with the calculated weight percentage of GSH in $\mathrm{Ag}_{16}(\mathrm{GSH})_{9}$. The weight percentage of ligand in D-AgNCs was estimated to be $70 \%$. After calculation, daptomycin accounted for $\sim 20 \%$ $(\mathrm{w} / \mathrm{w})$ in the D-AgNCs, giving 1:1 molar ratio of daptomycin and AgNCs within the D-AgNCs hybrid structure.

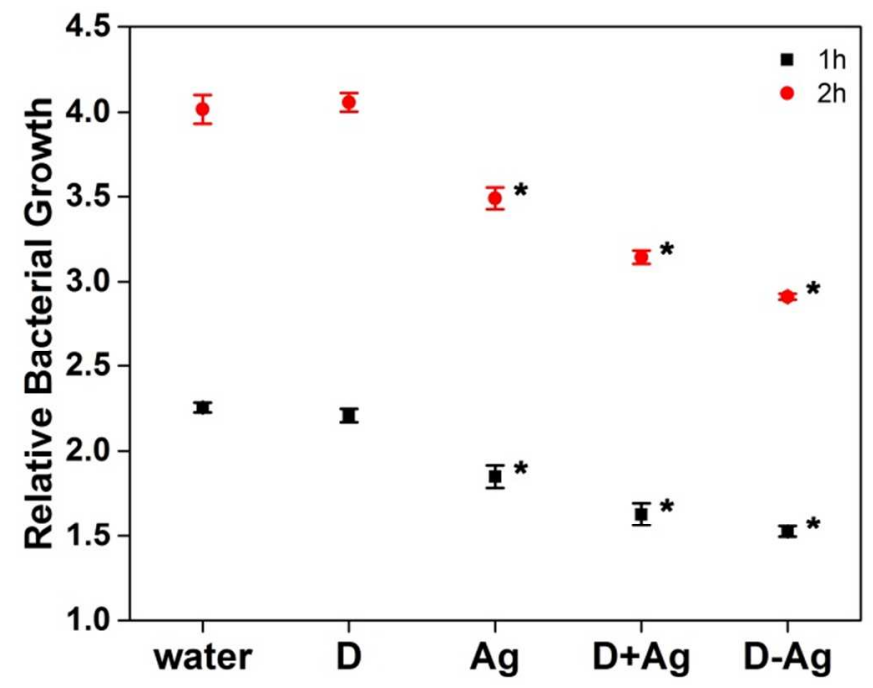

Figure S6. Relative bacterial growth after incubation of $1 \mathrm{~h}$ and $2 \mathrm{~h}$. Data are means \pm S.D., $\mathrm{n}=3$, Student's t-test, ${ }^{*}$ Significant against the water-treated group, $\mathrm{p}<0.05$. 


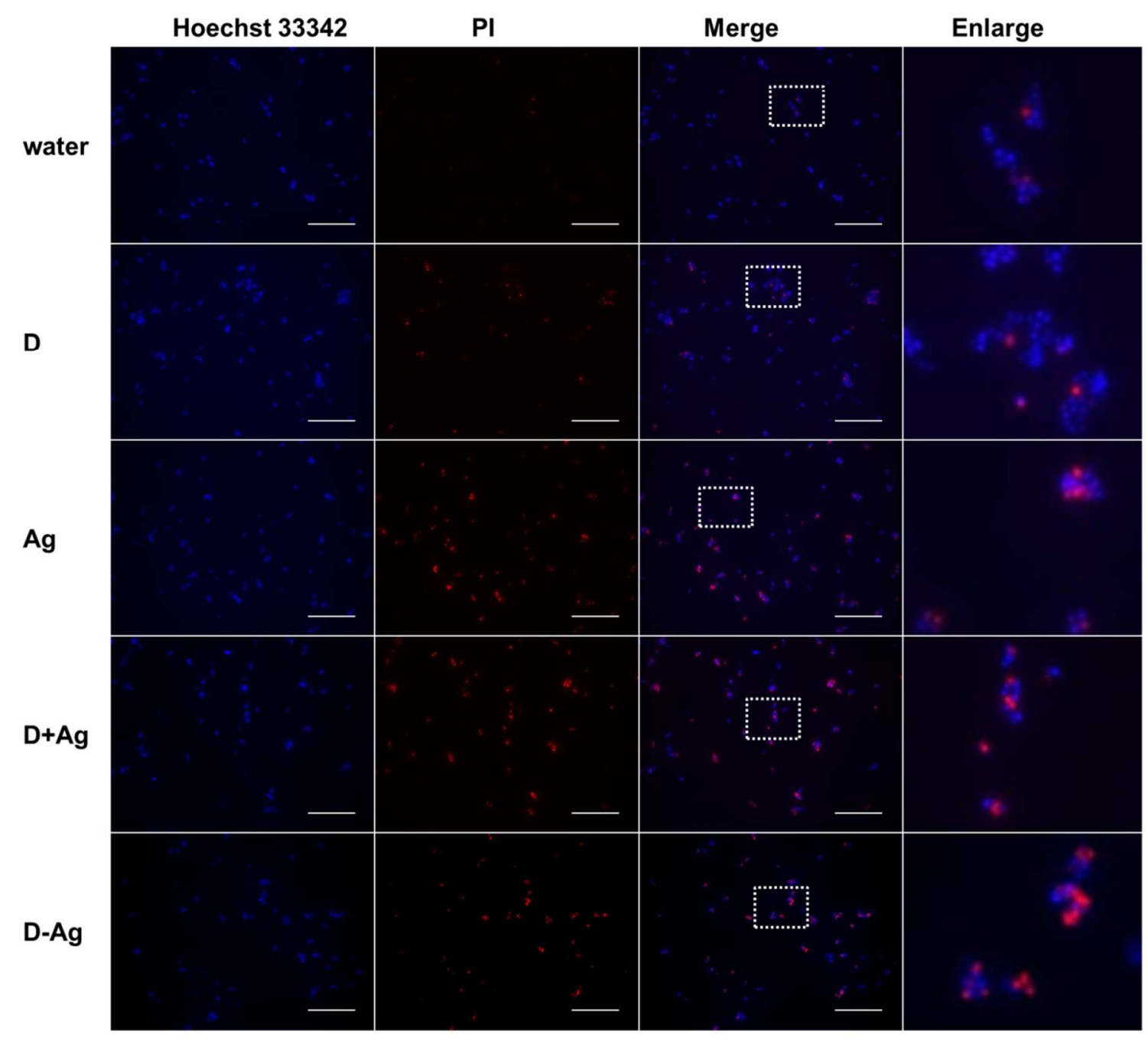

Figure S7. Representative fluorescence images of the bacterial cells after $2 \mathrm{~h}$ treatment. The dead cells were visualized by PI staining (red), while the Hoechst 33342 (blue) helped to identify all cells. Scale bar is $25 \mu \mathrm{m}$. 


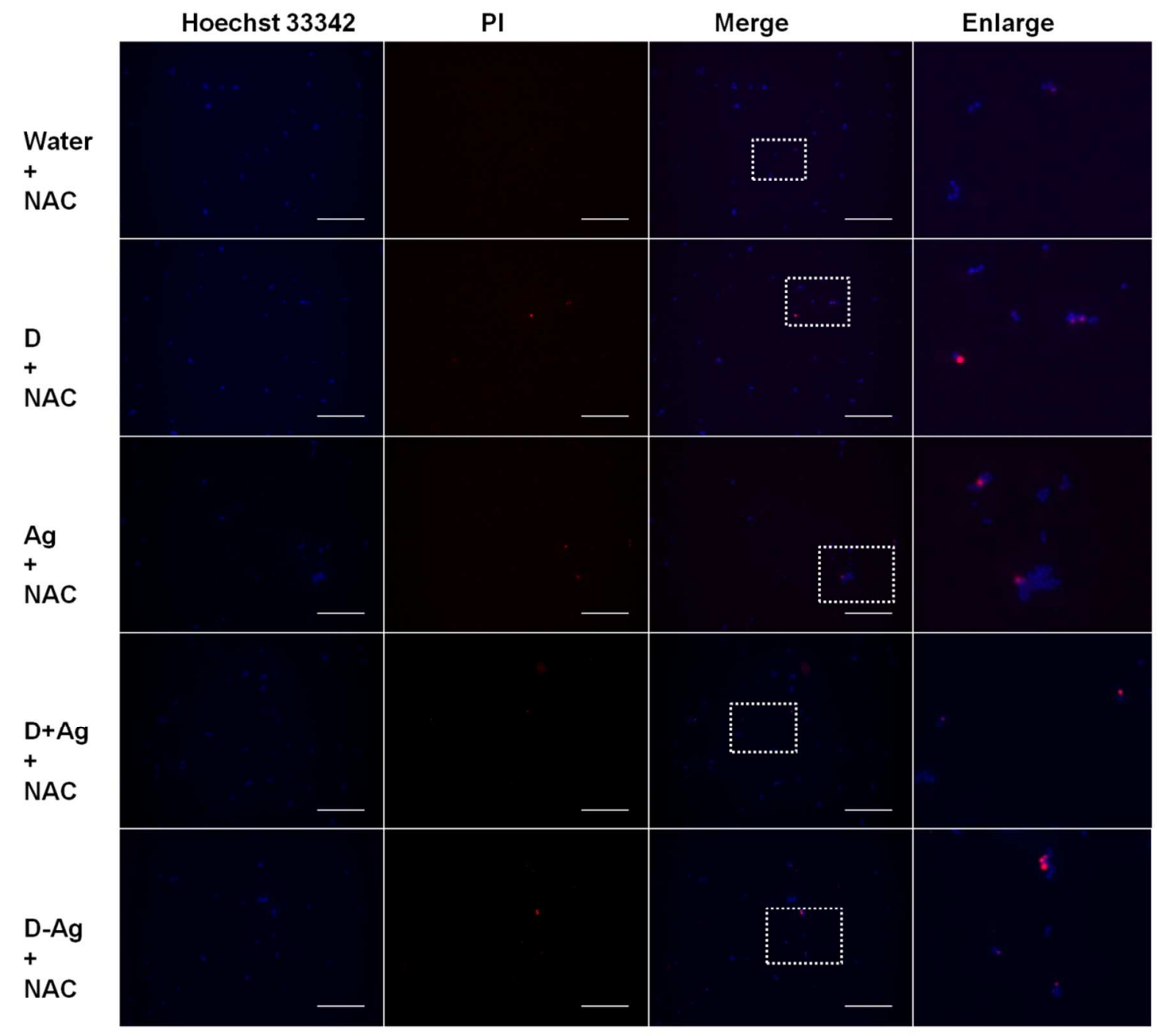

Figure S8. Representative fluorescence images of the bacterial cells after $2 \mathrm{~h}$ treatment in conjunction with $25 \mathrm{mM}$ NAC. The dead cells were visualized by PI staining (red), while the Hoechst 33342 (blue) helped to identify all cells. Scale bar is $25 \mu \mathrm{m}$. 


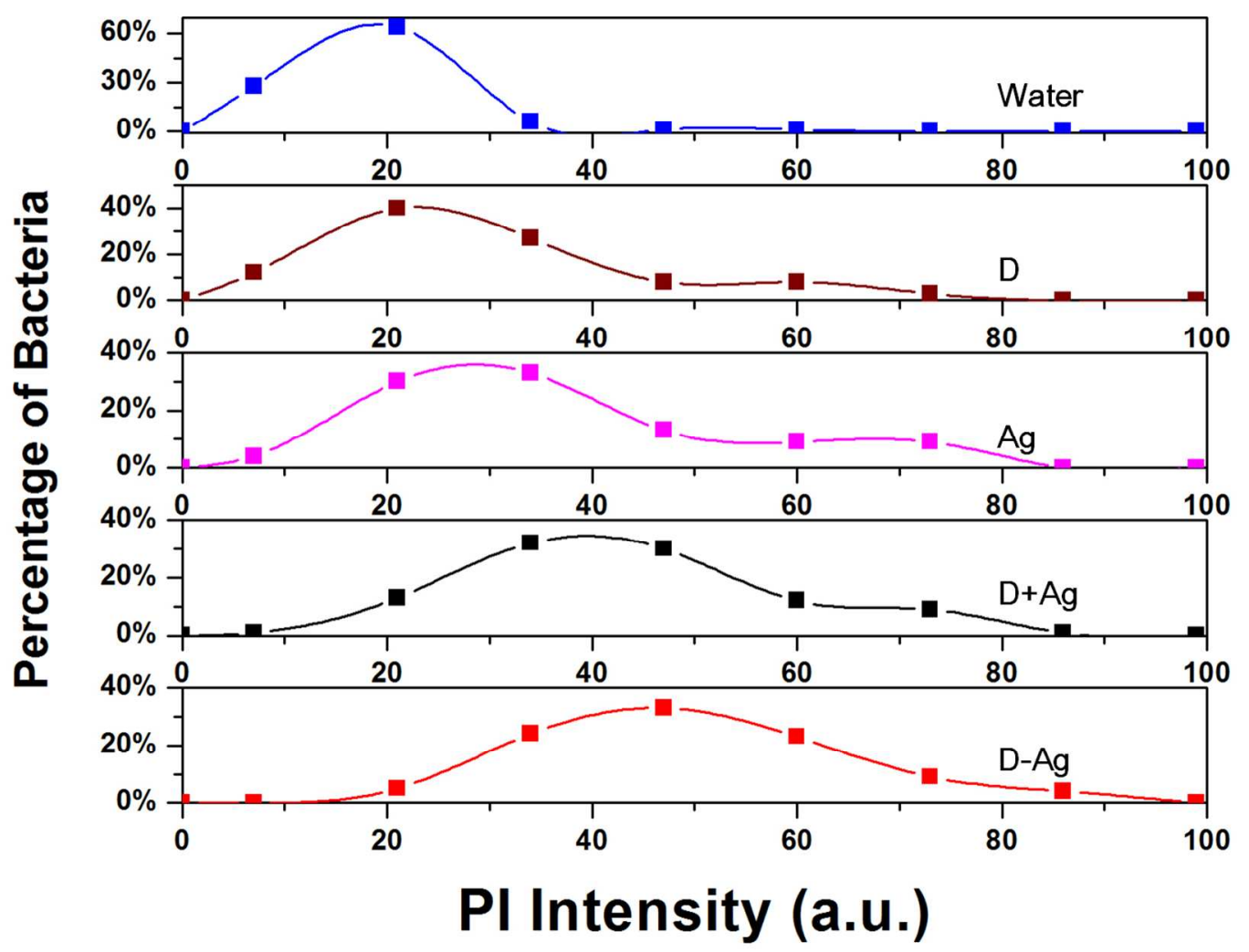

Figure S9. Histogram of the PI intensity in each individual treatment group. 


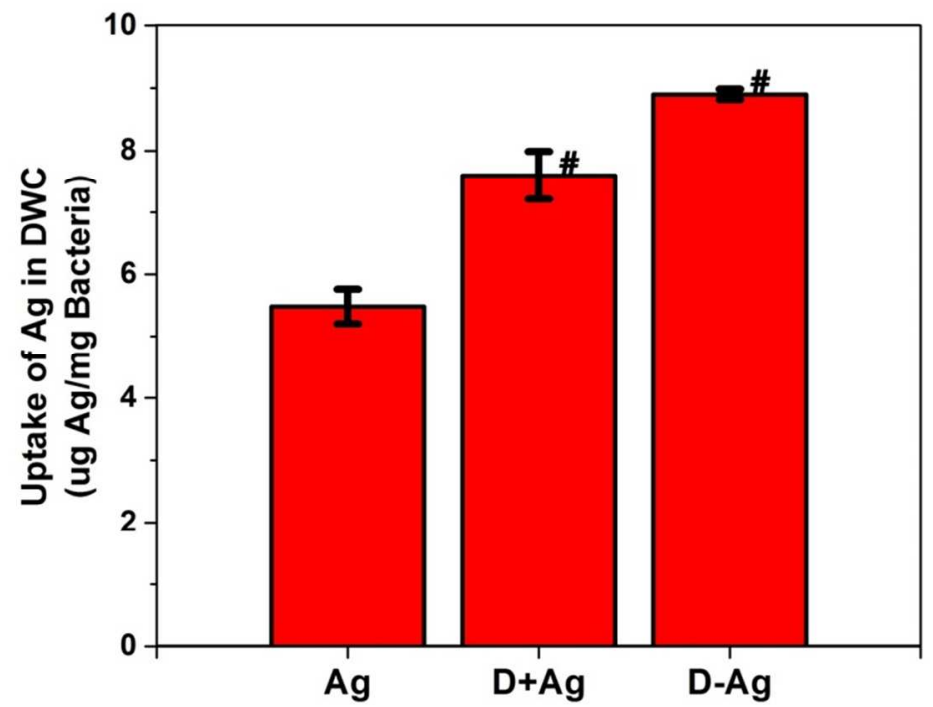

Figure S10. Uptake of Ag in bacteria after treatment with $\mathrm{Ag}, \mathrm{D}+\mathrm{Ag}$ and D-Ag for $2 \mathrm{~h}$. Data are means \pm S.D., $\mathrm{n}=3$, Student's t-test; \# Significant against the water-treated group, $\mathrm{p}<0.001$.

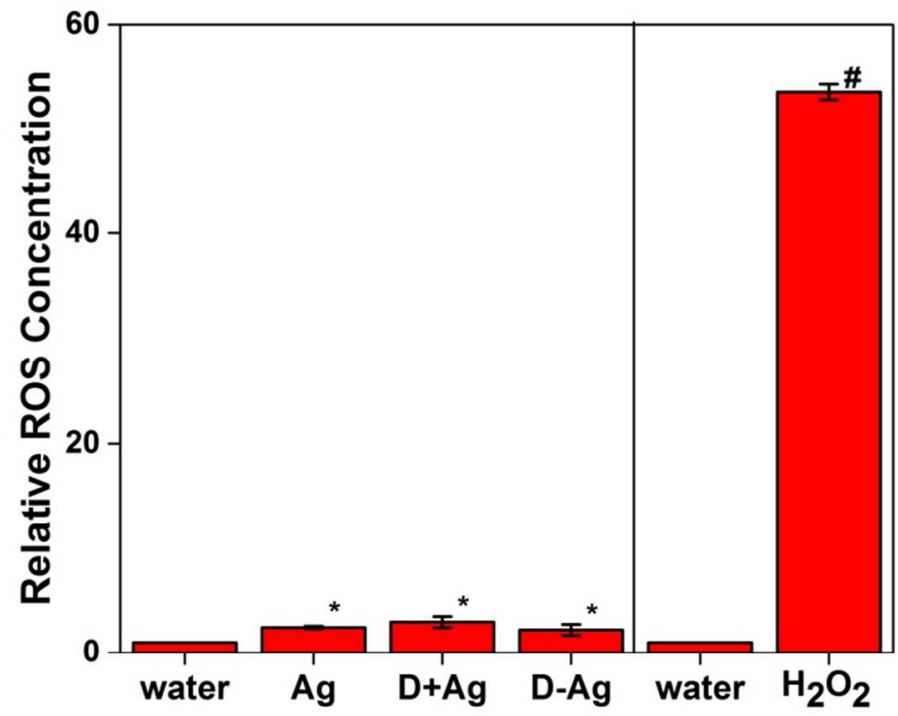

Figure S11. Relative abiotic ROS concentration generated by AgNCs after incubated in LB without bacteria for $2 \mathrm{~h}$, where all values were normalized against the water-treated group. Data are means \pm S.D., $n=3$, Student's t-test; * Significant against the water-treated group, $\mathrm{p}<0.05$; \# Significant against the water-treated group, $\mathrm{p}<0.001$. 